\title{
Nicotinic acid inhibits progression of atherosclerosis in mice through its receptor GPR109A expressed by immune cells
}

\author{
Martina Lukasova, ${ }^{1,2}$ Camille Malaval, ${ }^{1}$ Andreas Gille, ${ }^{2}$ Jukka Kero, ${ }^{2}$ and Stefan Offermanns ${ }^{1,2,3}$
}

1Department of Pharmacology, Max-Planck-Institute for Heart and Lung Research, Bad Nauheim, Germany.

2Institute of Pharmacology, University of Heidelberg, Heidelberg, Germany. ${ }^{3}$ Medical Faculty, Goethe University Frankfurt, Frankfurt, Germany.

\begin{abstract}
Nicotinic acid (niacin) is a drug used to reduce the progression of atherosclerosis. Its antiatherosclerotic activity is believed to result from lipid-modifying effects, including its ability to decrease LDL cholesterol and increase HDL cholesterol levels in plasma. Here, we report that in a mouse model of atherosclerosis, we found that nicotinic acid inhibited disease progression under conditions that left total cholesterol and HDL cholesterol plasma levels unaffected. The antiatherosclerotic effect was not seen in mice lacking the receptor for nicotinic acid GPR109A. Surprisingly, transplantation of bone marrow from GPR109A-deficient mice into atherosclerosis-prone animals also abrogated the beneficial effect of nicotinic acid. We detected expression of GPR109A in macrophages in atherosclerotic plaques. In macrophages from WT mice, but not from GPR109A-deficient animals, nicotinic acid induced expression of the cholesterol transporter ABCG1 and promoted cholesterol efflux. Furthermore, activation of GPR109A by nicotinic acid inhibited MCP-1-induced recruitment of macrophages into the peritoneal cavity and impaired macrophage recruitment to atherosclerotic plaques. In contrast with current models, our data show that nicotinic acid can reduce the progression of atherosclerosis independently of its lipid-modifying effects through the activation of GPR109A on immune cells. We conclude therefore that GPR109A mediates antiinflammatory effects, which may be useful for treating atherosclerosis and other diseases.
\end{abstract}

\section{Introduction}

Nicotinic acid has been used for decades as an antidyslipidemic drug to prevent and treat atherosclerosis $(1,2)$. Shortly after the discovery of the cholesterol-lowering effect of nicotinic acid by Altschul, its antiatherosclerotic effect was first observed in rabbits (3). Later, a reduction in atherosclerotic lesion size was also seen in other experimental animal models in response to nicotinic acid and its derivatives (4-7). The first evidence for antiatherosclerotic effects of nicotinic acid in humans came from angiographic studies showing regression of atherosclerosis in coronary and peripheral arteries under nicotinic acid treatment $(8,9)$. Furthermore, the Coronary Drug Project demonstrated a reduction in cardiovascular events and mortality in patients treated with nicotinic acid $(10,11)$. More recently, studies in which nicotinic acid was added to statin therapy have yielded promising data indicating that nicotinic acid enhances the effect of statins to reduce the risk of cardiovascular events and to slow the progression of atherosclerosis in patients with low levels of HDL cholesterol and established atherosclerotic cardiovascular disease (12-15).

Several mechanisms have been proposed to account for the antiatherosclerotic effects of nicotinic acid (16-18). The prevailing view holds the antidyslipidemic effects of nicotinic acid primarily accountable for its beneficial clinical effects. At pharmacological doses, nicotinic acid reduces LDL cholesterol, triglyceride, and lipoprotein(a) plasma levels while increasing levels of HDL cholesterol (1). One mechanism responsible for the lipid-modifying effects of nicotinic acid is the activation of the G-protein-coupled receptor GPR109A expressed on adipocytes (19-21). Activation of GPR109A

Conflict of interest: The authors have declared that no conflict of interest exists. Citation for this article: J Clin Invest doi:10.1172/JCI41651. on fat cells has an antilipolytic effect leading to a decreased release of free fatty acids from adipocytes. The reduced supply of free fatty acids to the liver then leads to reduced triglyceride synthesis, VLDL production, and LDL cholesterol levels (22). It has been proposed that the decrease in triglyceride content of ApoB-containing lipoproteins decreases the exchange of triglyceride for cholesteryl esters from HDL particles mediated by the cholesterol ester transfer protein (CETP), resulting in increased HDL cholesterol levels $(23,24)$. In fact, HDL cholesterol elevation in response to nicotinic acid in mice has been shown to depend on the presence of CETP $(25,26)$. However, the partial GPR109A agonist MK-0354 reduced plasma free fatty acid levels but failed to raise HDL cholesterol levels in humans $(27,28)$. While the lack of changes in HDL cholesterol levels could be due to the reduced efficacy of MK-0354 compared with nicotinic acid, it may also argue against a link between the antilipolytic effects of nicotinic acid and an increase in HDL cholesterol plasma levels. Another mechanism that might contribute to the increase in HDL cholesterol levels in response to nicotinic acid is a lowering of the hepatic uptake of ApoAI observed in vitro and in vivo in mice $(26,29)$ or an increased production of ApoAI as described in dyslipidemic humans (30). In addition, nicotinic acid at relatively high concentrations has been shown in vitro to inhibit diacylglycerol acyltransferase 2 (31); however, it remains unclear whether this effect is of significance under in vivo conditions.

Besides its lipid-modifying effects, nicotinic acid has various other activities that could be involved in its beneficial clinical effects. In endothelial cells, nicotinic acid has antioxidative and antiinflammatory effects and inhibits cytokine-induced expression of adhesion molecules and chemokines (32-34). These effects are unlikely to be directly mediated by the nicotinic acid receptor, as endothelial cells do not express GPR109A. GPR109A is 
A
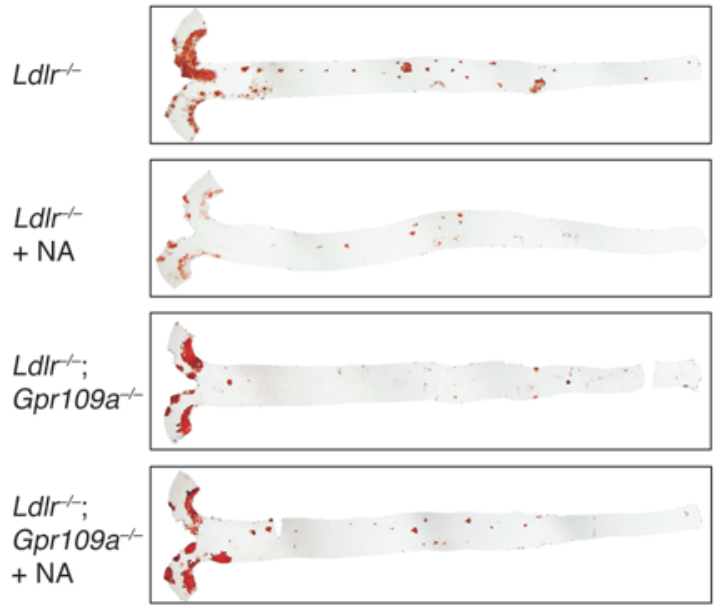

C

Ldl $r^{--}$
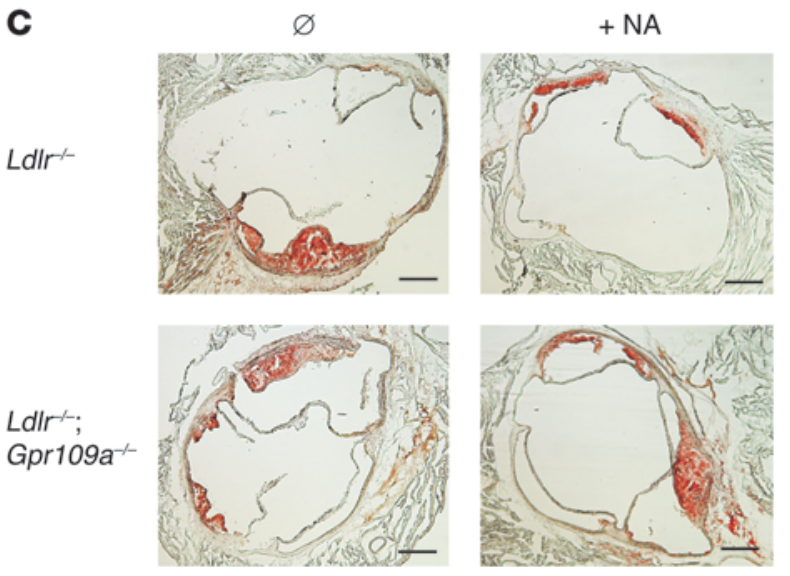

B

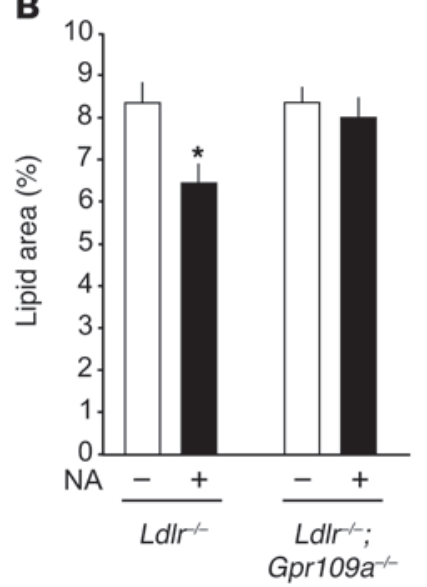

D

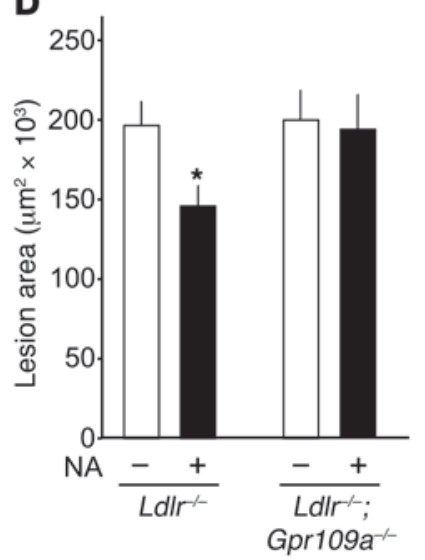

Figure 1

Effects of nicotinic acid on atherosclerotic plaque development in LdIr $^{-1-}$ and LdIr $r^{-1-}$;Gpr109a ${ }^{-/-}$mice. (A and C) Representative oil red O-stained aortae (A) and cryosections of mouse aortic roots (C) from untreated and nicotinic acid-treated (NA) $\mathrm{LdII}^{-1-}$ and LdIr $\mathrm{r}^{--}$;Gpr109a $\mathrm{a}^{-1-}$ mice. (B and $\mathbf{D})$ Mean atherosclerotic lesion areas of the aorta (B) and of sections of the aortic root (D) were determined by computer-assisted image analysis. Data are presented as average lesion size in percentage of the total surface of the aorta or as the absolute lesion area on the aortic root. At an age of 8 weeks, animals were treated with a high-fat diet without or with $0.3 \%$ nicotinic acid. After 10 weeks of treatment, animals were sacrificed and analyzed. Animal numbers per group were between 8 and 12. Shown are mean values \pm SEM; ${ }^{*} P \leq 0.05$ (versus $L d / r^{-1-}$-NA and $\mathrm{LdII}^{-1-} ;$ Gpr109a $\left.{ }^{-1-}+\mathrm{NA}\right)$. Scale bars: $300 \mu \mathrm{m}$. not only expressed in adipocytes but also in various immune cells including macrophages, neutrophils, and epidermal Langerhans cells, but not in lymphocytes (35-38). In leukocytes, nicotinic acid induces cellular effects, such as an increase in the intracellular $\mathrm{Ca}^{2+}$ concentration or an increased formation of prostanoids (39-43). In monocyte/macrophage cell lines, nicotinic acid stimulates PPAR $y$ expression and enhances transcription of the oxidized LDL (oxLDL) scavenger receptor CD36 and of the cellular cholesterol efflux transporter ABCA1 $(44,45)$. Whether direct effects of nicotinic acid on inflammatory cells contribute to the antiatherosclerotic effects of nicotinic acid remains, however, unknown.

The present study was undertaken in order to elucidate the mechanisms underlying the antiatherosclerotic effects of nicotinic acid. Using mice lacking the nicotinic acid receptor GPR109A and generating bone marrow chimeras, we show that nicotinic acid reduces the progression of atherosclerosis by direct GPR109Amediated effects on bone marrow-derived cells. These data indicate that in addition to the antidyslipidemic effects of nicotinic acid, a direct antiinflammatory effect of nicotinic acid, which is mediated through GPR109A on immune cells, underlies the beneficial effects of this antiatherosclerotic drug.

\section{Results}

Nicotinic acid inhibits the progression of atherosclerosis through its receptor GPR109A. In order to study the antiatherosclerotic effects of nicotinic acid in a rodent model accessible to genetic manipulations, we tested atherosclerosis-prone mice lacking the LDL receptor (LDL-R). Treatment of male LDL-R-deficient mice kept on a high-fat diet (containing $1.5 \%$ cholesterol) with nicotinic acid reduced atherosclerotic lesion formation significantly (Figure 1). At a concentration of $0.3 \%$ nicotinic acid, a dose used before in mice $(25,26)$, the effect was maximal, and body weight as well as food intake were indistinguishable between treated and nontreated animals (data not shown). Nicotinic acid reduced atherosclerotic lesion size by about $25 \%$ in all regions of the aorta (Figure 1 ).

To test whether the effect of nicotinic acid involved the nicotinic acid receptor GPR109A, we performed parallel experiments

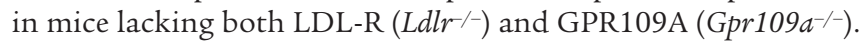
Whereas the extent of atherosclerotic lesion development was comparable in nontreated high-fat diet-fed $\mathrm{Ldlr}^{-1-} ; \mathrm{Gpr}^{109^{+/+}}$and

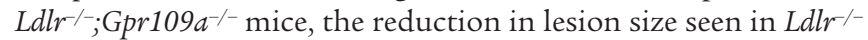
animals treated with nicotinic acid was absent in mice also lacking GPR109A (Figure 1). Thus, the nicotinic acid receptor is critically involved in the antiatherosclerotic effect of nicotinic acid in LDL-R-deficient mice.

Effect of nicotinic acid on plasma lipid levels in atherosclerosis-prone mice. Nicotinic acid is believed to exert its antiatherosclerotic effects in humans through a decrease in total cholesterol and an increase in HDL cholesterol levels $(1,2)$. Since nicotinic acid failed to induce corresponding changes in plasma lipid levels in WT and ApoE-deficient mice as well as in various other animal species $(46,47)$, we evaluated the effect of nicotinic acid on 
A
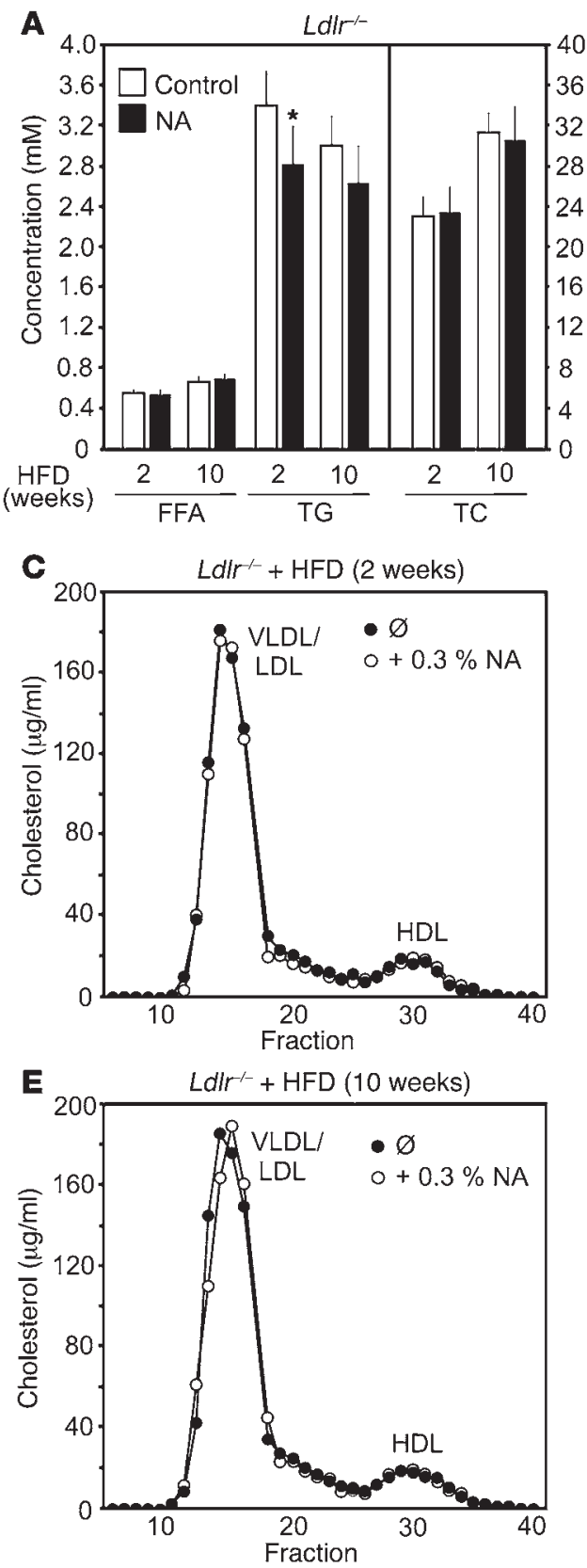

\section{B}
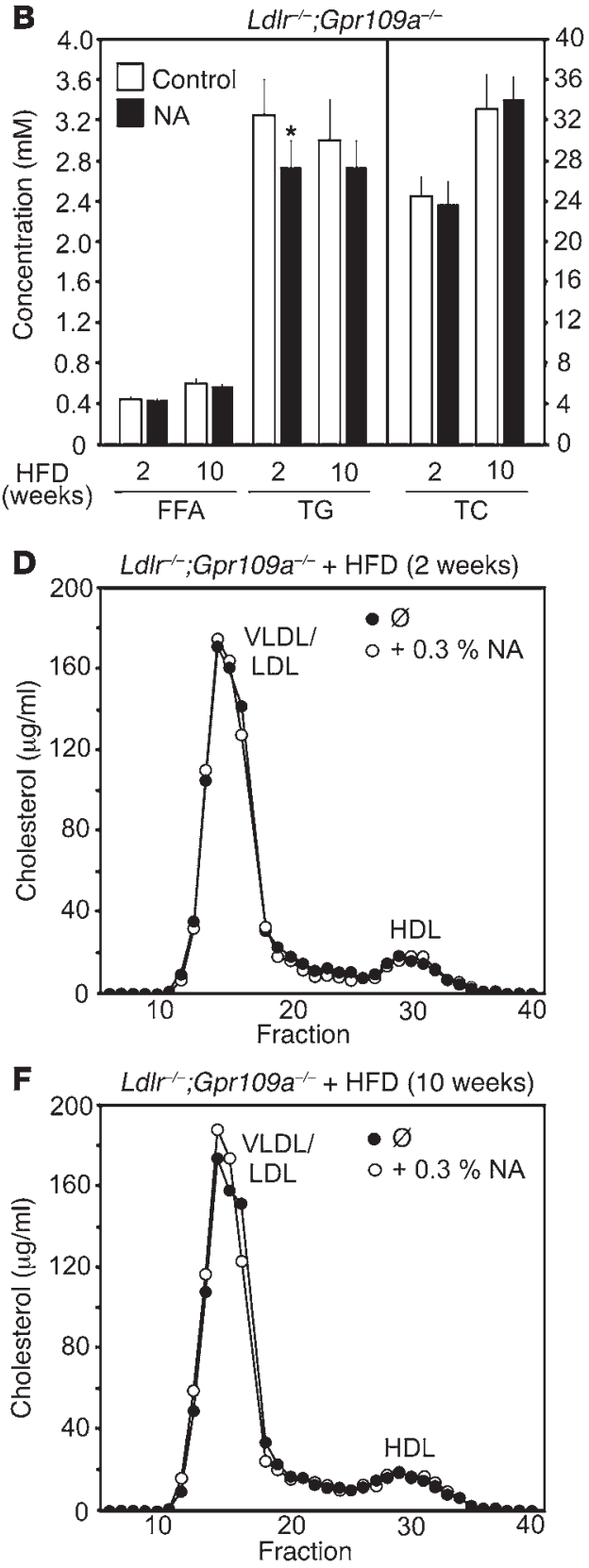

Figure 2

Effect of nicotinic acid on plasma lipid levels in $\mathrm{Ldll}^{-/}$and $\mathrm{LdII}^{-1-}$; Gpr109a-/- mice. Ldlr-/- and Ldlr $^{-1-} ; G_{p r 109 a^{-/-}}$mice were treated at an age of 8 weeks for 2 weeks (A-D) or 10 weeks (A, B, E, and F) with high-fat diet (HFD) in the absence or presence of $0.3 \%$ nicotinic acid. Thereafter, free fatty acid, triglyceride (TG), and total cholesterol (TC) levels were determined ( $\mathbf{A}$ and $\mathbf{B})$. Shown are mean values of the indicated plasma lipid levels \pm SEM; ${ }^{*} P \leq 0.05$ compared with control value. (C-F) Serum samples from the indicated high-fat diet-fed animals treated without or with $0.3 \%$ nicotinic acid were pooled and analyzed for lipoprotein cholesterol profiles by FPLC as described in Methods. Shown are representative examples of at least 3 independently performed experiments. the plasma concentrations of various lipid fractions in LDL-Rdeficient mice kept on a high-fat diet for 2 or 10 weeks. $\mathrm{Ldlr}^{-1-}$;

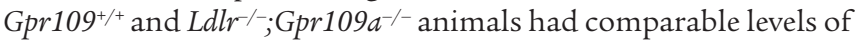
free fatty acids, triglycerides, total cholesterol, and HDL cholesterol. Of these parameters, only triglyceride levels showed a small reduction, by $11 \%-18.5 \%$, in response to 2 weeks of nicotinic acid treatment (Figure 2, A and B). Size exclusion chromatography

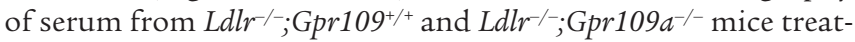
ed with normal chow or with a high-fat diet in the absence or presence of nicotinic acid showed no significant change in the distribution of cholesterol among VLDL, LDL, and HDL fractions (Figure 2, C-F). The phospholipid as well as the ApoAI and ApoAII content of HDL particles was not affected by nicotinic acid treatment (see Supplemental Figure 1; supplemental material available online with this article; doi:10.1172/JCI41651DS1).
Thus, GPR109A-dependent antiatherosclerotic effects of nicotinic acid were not accompanied by any changes in cholesterol or HDL cholesterol plasma concentrations.

GPR109A on bone marrow-derived cells mediates the antiatherosclerotic effects of nicotinic acid. Since GPR109A is not only expressed in adipocytes but also in various immune cells, we generated bone marrow chimeras by transplanting bone marrow from WT or GPR109A-deficient mice onto irradiated $\mathrm{Ldlr}^{/-}$animals. 2 weeks after the transplantation, mice were put on a high-fat diet in the absence or presence of $0.3 \%$ nicotinic acid. Similar to nontransplanted animals, nicotinic acid had no effect on plasma lipid levels in $\mathrm{Ldlr}^{-/-}$mice transplanted with WT or GPR109A-deficient bone marrow (see Supplemental Figure 2). 16 weeks after the beginning of a high-fat diet, atherosclerotic lesion sizes were evaluated (Figure 3). In mice that had received WT bone marrow, nicotinic 
A

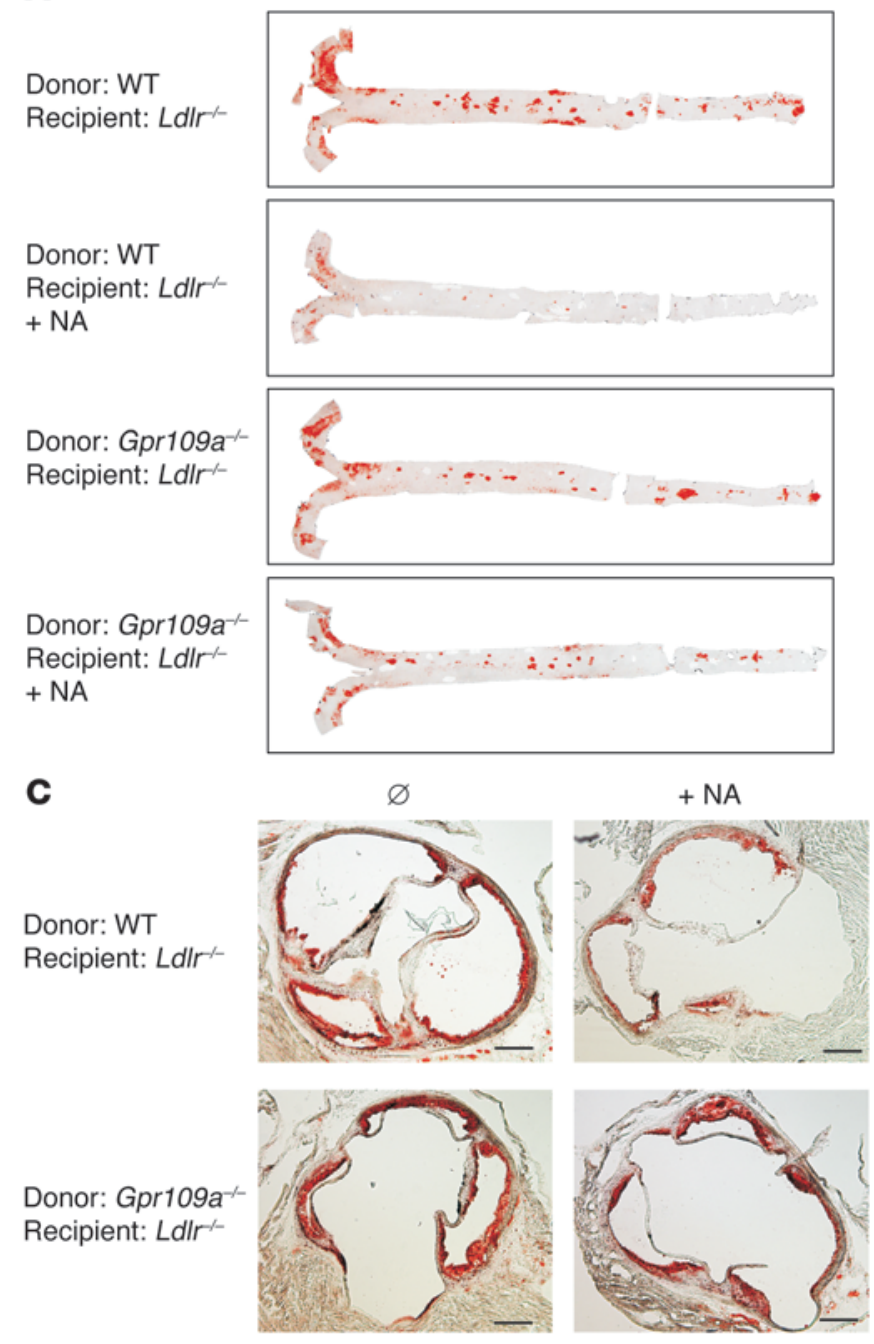

B
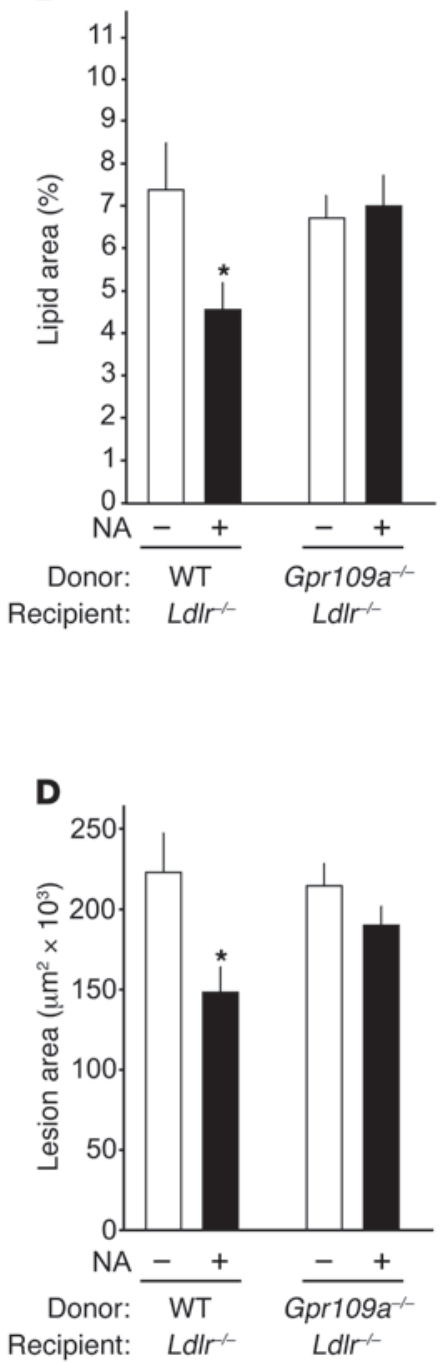

Figure 3

Effect of nicotinic acid on progression of atherosclerosis in Ldlr-1- mice carrying WT or GPR109A-deficient bone marrow. Ldlr-1- mice at an age of 8 weeks were irradiated and transplanted with bone marrow from WT or GPR109A-deficient mice (Gpr109a ${ }^{-/-}$). 2 weeks after the bone marrow transplantation, animals were put on a high-fat diet in the absence or presence of $0.3 \%$ nicotinic acid. After 16 weeks, animals were sacrificed and atherosclerotic lesion sizes were evaluated. Shown are representative oil red O stains of whole-mount aortae (A) and of cryosections of mouse aortic roots $(\mathbf{C})$ as well as the statistical evaluation of the quantification of lesion sizes in the aorta (B) and in the aortic root (D). Number of animals per group were 10-17; shown are mean values \pm SEM. ${ }^{*} P<0.05$ (compared with non-NA-treated Ldlr ${ }^{-1}$ mice transplanted with WT bone marrow). Scale bars: $300 \mu \mathrm{m}$.

acid treatment resulted in a significant reduction of atherosclerotic lesion size in all areas of the aorta comparable to that of nontransplanted $\mathrm{Ldlr}^{-/-}$animals. Interestingly, this effect was not seen in mice that had received bone marrow from GPR109A-deficient animals (Figure 3). This indicates that the antiatherosclerotic effect of nicotinic acid in $\mathrm{Ldlr}^{-/}$mice depends on GPR109A expressed on bone marrow-derived cells.

GPR109A is expressed by macrophages in atherosclerotic plaques. To further characterize cells that express GPR109A and may be involved in the antiatherosclerotic effects of nicotinic acid, we have generated a BAC-based transgenic mouse line expressing monomeric red fluorescent protein (mRFP) under the control of the mouse Gpr109a promoter (Gpr109amRFP) (48). In 5 independent transgenic lines, we found expression of $\mathrm{mRFP}$ in adipocytes and in various tissues containing immune cells such as spleen or bone marrow (data not shown) reflecting the known expression pattern of GPR109A. To determine whether GPR109A-expressing cells are present in atherosclerotic lesions, we crossed the GPR109A reporter mouse line with LDL-R-deficient mice. Gpr109 $a^{m R F P} ; \mathrm{Ldl}^{-/}$animals received a high-fat diet for 16 weeks, and thereafter whole aortae and aortic root sections of atherosclerotic lesions were analyzed by fluorescence microscopy (Figure 4). As shown in Figure 4A, strong RFP fluorescence was seen in whole-mount aortae from atherosclerotic mice carrying the GPR109A reporter transgene but not in whole-mount aortae from atherosclerotic $\mathrm{Ldlr}^{-/}$mice without the Gpr109 $a^{m R F P}$ transgene and from mice that were not atherosclerotic but carried the GPR109A reporter transgene ( $\mathrm{Ldlr}^{+/+}$; Gpr109amRFP). To further characterize the GPR109A-expressing cells in atheroscle- 
A

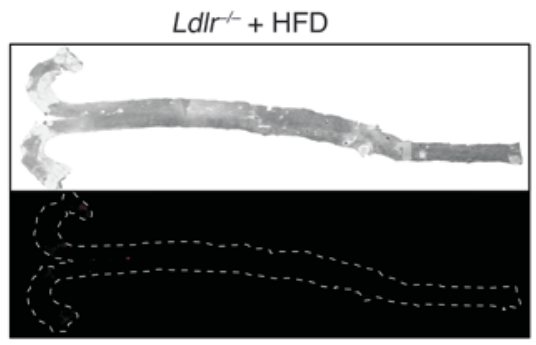

Ldlr $r^{-2} ; G p r 109 a^{\text {mRFP }}+\mathrm{HFD}$

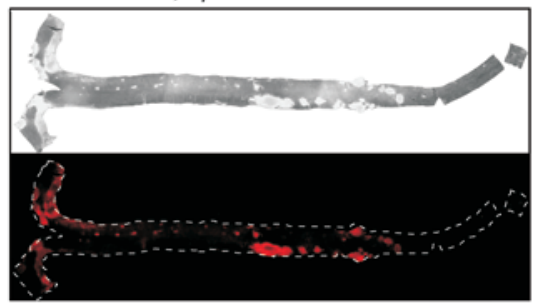

$L d l r^{+/+} ; G p r 109 a^{\text {mRFP }}+$ HFD

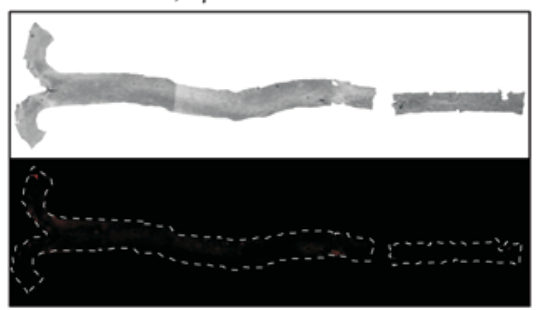

B

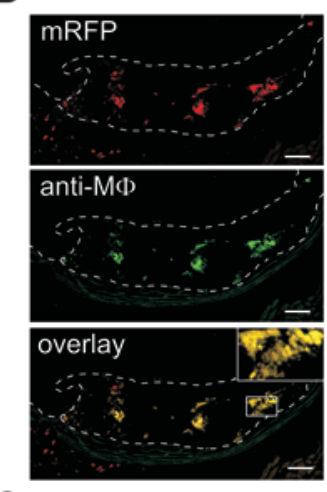

C

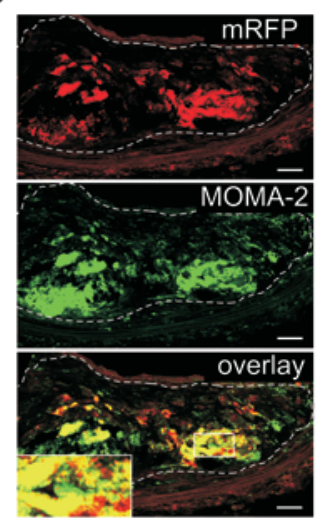

Figure 4

Expression of GPR109A in atherosclerotic lesions. Ldlr ${ }^{-1}$ mice and $L d l r^{-1}$ mice carrying in addition a BAC transgene expressing mRFP under the control of the Gpr109a promoter (Gpr109a ${ }^{\text {mRFP }}$ ) as well as WT mice carrying only the Gpr109a reporter transgene ( $\left.L d l r^{+/+} ; G p r 109 a^{m R F P}\right)$ received a high-fat diet for 16 weeks. Thereafter, animals were sacrificed, and whole-mount preparations of the aortae were photographed by normal light microscopy (A, upper panel) as well as by fluorescence microscopy to visualize mRFP expression as an indicator of Gpr109a promoter activity (A, lower panels). (B and $\mathbf{C}$ ) Photomicrographs of Ldlr ${ }^{--}$;Gpr109amRFP mouse aortic root cryosections showing atherosclerotic plaques. Immunofluorescence labeling was performed with antibodies recognizing macrophages (anti-M $\phi, M O M A-2$ ), and mRFP fluorescence was detected in parallel to visualize GPR109A expression. The analysis of atheroma from 3 different mice showed similar results. Margins of aortae $(\mathbf{A})$ and atheroma (B and $\mathbf{C}$ ) are marked with broken white lines. Scale bars: $37 \mu \mathrm{m}$ (B); $18.5 \mu \mathrm{m}$ (C). Insets in $\mathbf{B}$ and $\mathbf{C}$ show magnifications (3-fold) of the indicated areas in the overlays. rotic lesions, we sectioned lesions and stained them with antibodies recognizing murine macrophages. Overlays of images indicate that most plaque areas that were RFP-positive corresponded to areas that were stained for macrophage antigens (Figure 4, B and C). These data show that GPR109A expression is strongly increased in atherosclerotic lesions of $\mathrm{Ldlr}^{-/}$mice and that this appears to be due to the presence of GPR109A-expressing macrophages.

Effects of nicotinic acid on macrophages. We then tested whether nicotinic acid has effects on macrophages that might explain its inhibitory activity on the development of atherosclerosis. In isolated macrophages, we observed a small but nonsignificant effect of nicotinic acid on the expression of the cholesterol transporter ABCA1. However, nicotinic acid strongly induced expression of ABCG1 in isolated macrophages as well as in atherosclerotic vessels, an effect not seen in the absence of GPR109A (Figure 5, A and B). The upregulation of ABCG1 by nicotinic acid was accompanied by a significant increase in cholesterol efflux from WT macrophages to HDL3, whereas nicotinic acid had no effect on cholesterol efflux in macrophages from Gpr109a $a^{-/-}$mice (Figure 5C).

To determine whether nicotinic acid is able to affect the expression of inflammatory markers in macrophages, we treated cells with IFN- $\gamma$, resulting in a several-fold increase in monocyte chemotactic protein-1 (MCP-1) expression. Nicotinic acid strongly inhibited this effect in macrophages from WT but not from GPR109A-deficient mice (Figure 6A). Immunostaining of atherosclerotic plaques from untreated and nicotinic acid-treated mice showed that the relative fluorescence intensity of MCP-1 in MOMA-2-positive plaque areas was strongly reduced by nicotinic acid (Figure 6B), indicating that nicotinic acid reduces MCP-1 expression under in vivo conditions also. We then costained plaque macrophages in untreated and nicotinic acid-treated mice with anti-CD68 antibodies and antibodies recognizing arginase- 1 and arginase- 2 to determine whether nicotinic acid treatment has an effect on the differentiation state of plaque macrophages (49). While nicotinic acid had no effect on the expression of arginase-1, a marker for M2-like differentiation, nicotinic acid strongly reduced the relative fluorescence intensity of arginase-2 versus CD68 levels in a GPR109A-dependent manner (Figure 6C), indicating that nicotinic acid induces reduced M1-like differentiation via GPR109A.

To analyze potential effects of nicotinic acid on the MCP-1dependent chemotaxis of macrophages in vivo, we determined macrophage recruitment into the peritoneal cavity in response to MCP-1 (Figure 6D). MCP-1 treatment resulted in the accumulation of macrophages both in WT and GPR109A-deficient mice, and administration of nicotinic acid blocked this effect in WT mice. However, in GPR109A-deficient mice, nicotinic acid was without effect. To determine whether the recruitment, migration, and homing of macrophages into atherosclerotic plaque was also affected by nicotinic acid, we labeled WT and Gpr109a-/- macrophages from untreated and nicotinic acid-treated mice with quantum dot nanocrystals exhibiting different fluorescence emission maxima. 2 days after adoptive transfer into atherosclerotic $\mathrm{Ldlr}^{-/}$mice, comparable numbers of untreated WT and Gpr109a $\mathrm{a}^{-/-}$ macrophages were detected in plaques of $\mathrm{Ldlr}^{-/-}$mice (Figure 6E). Nicotinic acid reduced the recruitment of WT but not of GPR109Adeficient cells into atherosclerotic lesions by $75 \%$ (Figure 6E). Consistent with reduced recruitment of macrophages into atherosclerotic lesions under nicotinic acid treatment, we found less macrophage infiltration, as determined by quantification of CD68-positive cells (Figure 6F). 
A

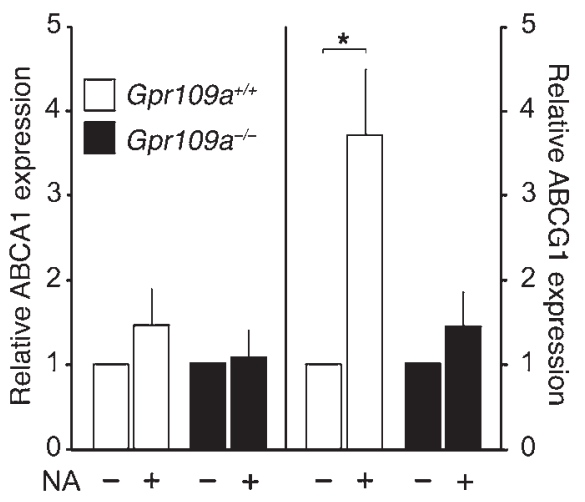

B

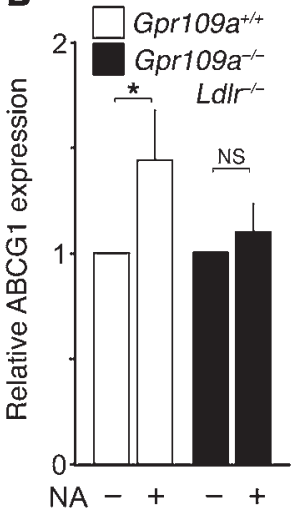

C

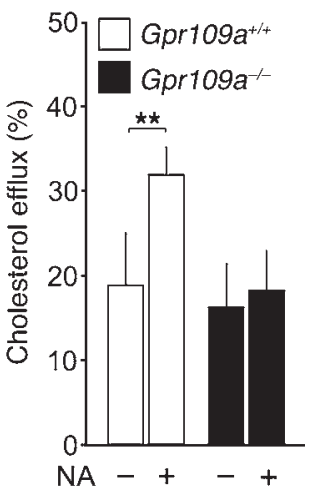

Figure 5

Effect of nicotinic acid on gene expression and cholesterol efflux in WT and Gpr109a ${ }^{-/-}$mice. (A) Peritoneal macrophages from WT (Gpr109a ${ }^{+/+}$) or GPR109A-deficient mice (Gpr109a ${ }^{-/-}$) were treated for 4 hours in the absence or presence of $100 \mu \mathrm{M}$ nicotinic acid. Thereafter, expression of ABCA1 (left panel) or ABCG1 (right panel) was determined as described in Methods. Shown are mean values \pm SEM $(n=6)$. (B) ABCG1 expression in aortic arches of $L d l r^{-1-} ; G p r 109 a^{+/+}$and $L d l r^{--} ; G p r 109 a^{-/-}$mice kept on a high-fat diet for 8 weeks and treated without or with nicotinic acid. Shown are mean values \pm SEM $(n \geq 8)$. (C) HDL-dependent cholesterol efflux from macrophages prepared from WT and GPR109A-deficient mice (Gpr109a $\left.{ }^{-/}\right)$treated without or with $0.3 \%$ nicotinic acid. Shown is the cholesterol efflux after 1 hour as percentage of the total cholesterol present in the cells at the beginning of the experiment. Shown are mean values $\pm \operatorname{SEM}(n=6)$. Shown are data from at least 5 different animals. ${ }^{*} P \leq 0.05 ;{ }^{* *} P \leq 0.01$.

To analyze whether differences in vascular expression of adhesion molecules might contribute to the reduced homing of macrophages to atherosclerotic lesions in nicotinic acid-treated animals, we determined the effect of nicotinic acid on the expression of VCAM-1, ICAM-1, and P-selectin in atherosclerotic vessels of $\mathrm{Ldl} / \mathrm{r}$ mice transplanted with WT or Gpr109a-/- bone marrow (Figure 6G). While nicotinic acid had no effect on ICAM-1 mRNA levels, levels of VCAM-1 and P-selectin were reduced by $65 \%$ and $50 \%$, respectively, in mice with WT bone marrow. Interestingly, the reduction in VCAM-1 and P-selectin expression was not seen in $\mathrm{Ldlr}^{-/}$animals that had received Gpr109a-/- bone marrow (Figure 6G).

\section{Discussion}

The pharmacological normalization of plasma levels of LDL cholesterol and HDL cholesterol is currently the most important therapeutic strategy to inhibit the progression of atherosclerosis $(50,51)$. The oldest antidyslipidemic drug, nicotinic acid, has recently attracted renewed interest, as it alters plasma levels of all lipids in directions that are expected to be beneficial for the prevention and treatment of atherosclerosis and since it is the most efficacious HDL cholesterol-elevating drug $(17,52,53)$. Here, we report that nicotinic acid has a strong lipid-independent inhibitory effect on the progression of atherosclerosis that is mediated by its receptor GPR109A on bone marrow-derived cells.

Raising plasma HDL cholesterol levels has been a therapeutic goal since epidemiological data indicated an inverse correlation between HDL cholesterol levels and the risk for coronary heart disease $(54,55)$. However, direct evidence that increasing HDL cholesterol plasma levels reduces cardiovascular disease is still missing. Recent experimental and clinical data have shown that the relationship between HDL cholesterol and protection from cardiovascular disease is more complex and that not only the plasma level of HDL but also the composition of HDL particles may be an important factor (56-58). The inhibition of atherosclerosis progression by nicotinic acid in the mouse model used in the study was not accompanied by any change in HDL cholesterol or total cholesterol. There was a small decrease in triglyceride plasma levels 2 weeks after the beginning of nicotinic acid treatment, which was not seen any more after 10 weeks of treatment. It is unlikely that the transient effect of nicotinic acid on triglyceride levels strongly contributed to the antiatherosclerotic effect, since the inhibition of atherosclerosis strongly depended on the presence of the nicotinic acid receptor on bone marrow-derived cells. In addition, a small decrease in triglyceride levels after 2 weeks of nicotinic acid treatment was also observed in mice lacking the nicotinic acid receptor, although these animals did not show a reduced progression of atherosclerosis in response to nicotinic acid treatment. We therefore conclude that the beneficial effects of nicotinic acid are not only mediated through alterations in plasma lipid levels but also involve direct effects on immune cells.

GPR109A has been described as expressed in various differentiated bone marrow-derived cells including macrophages, Langerhans cells, and neutrophils, but not lymphocytes $(35,36,38)$. Since macrophages within atherosclerotic lesions express GPR109A and since GPR109A on bone marrow-derived cells is required for the antiatherosclerotic effect of nicotinic acid, nicotinic acid may directly affect the function of plaque macrophages. Nicotinic acid has been shown to increase the transcriptional activity of PPAR $\gamma$ and to induce expression of the scavenger receptor $\mathrm{CD} 36$ and of the cholesterol transporter ABCA1 in monocyte/macrophage cell lines $(44,45)$. While we did not observe a significantly increased expression of CD36, PPAR $\gamma$, or ABCA1 in nicotinic acid-treated isolated murine macrophages, nicotinic acid increased the expression of the ABCG1 transporter in macrophages from WT but not from GPR109A-deficient animals (Figure 5 and data not shown). Interestingly, an isolated upregulation of ABCG1 was recently also reported in macrophages induced by the chemokine CXCL4 (59). Together with our data indicating a reduced arginase- 2 expression in nicotinic acid-treated macrophages in vivo, these data show that nicotinic acid can change the differentiation state of macrophages both in vitro and in vivo. Both ABCA1 and ABCG1 mediate the transport of cellular cholesterol to ApoAI-containing HDL particles for the reverse cholesterol transport pathway (60). In isolated macrophages, we observed that nicotinic acid pretreatment enhanced 


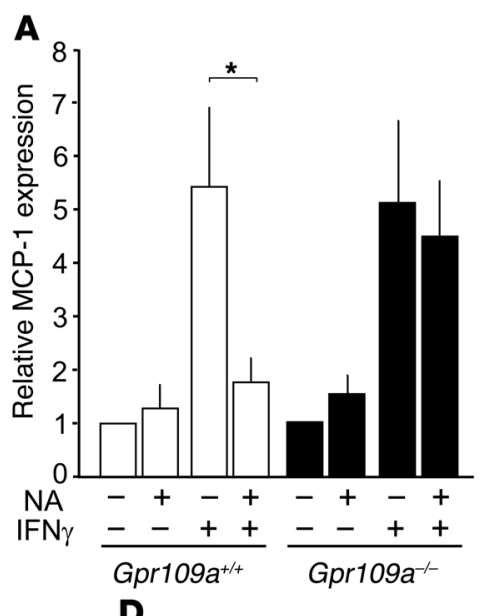

D

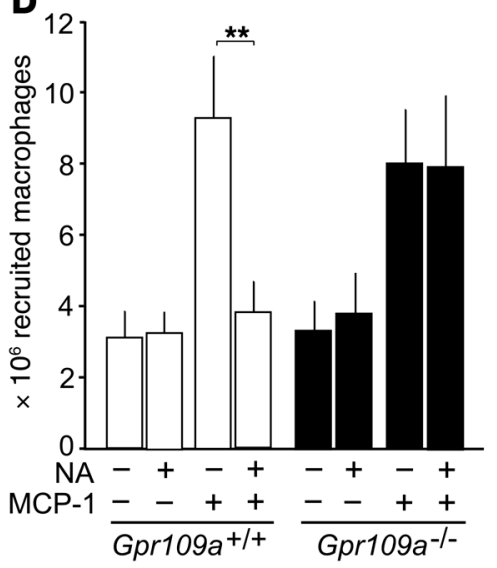

B

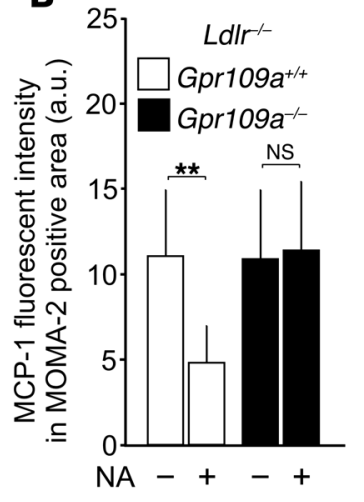

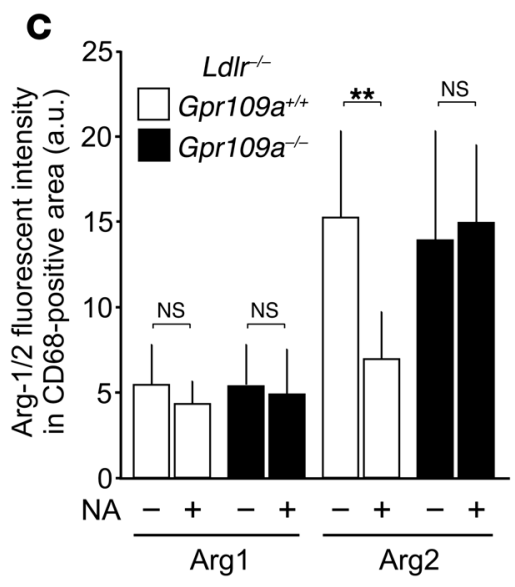

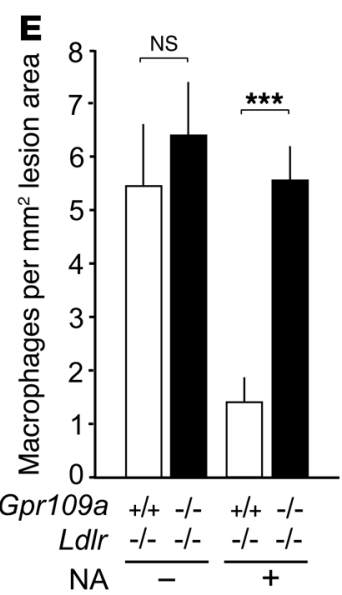

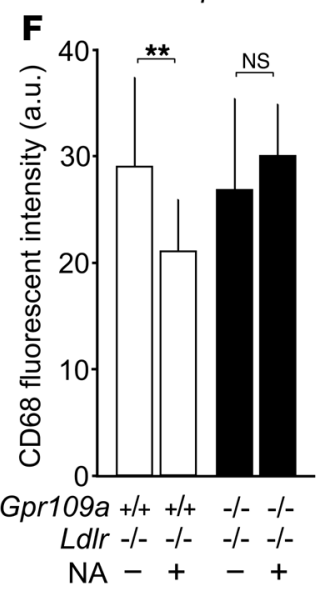

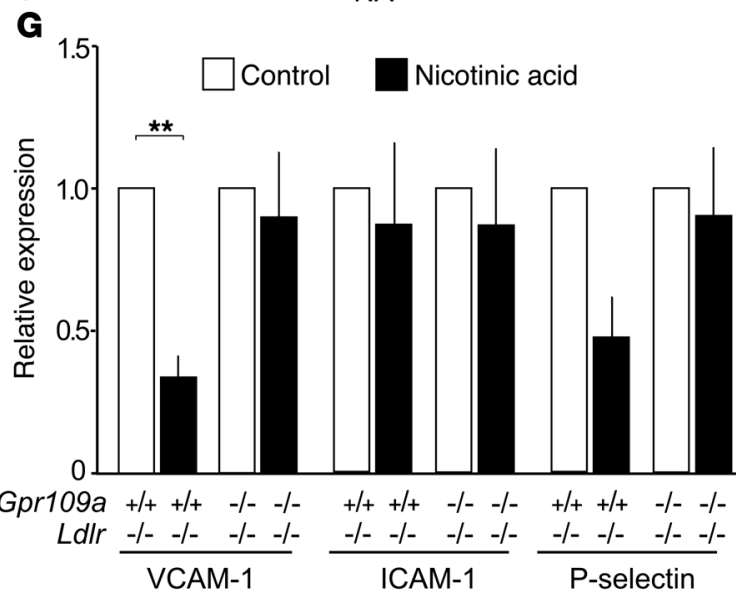

Figure 6

Effect of nicotinic acid on gene expression and macrophage recruitment in WT and Gpr109a ${ }^{-/-}$mice. (A) Peritoneal macrophages from WT or GPR109A-deficient mice (Gpr109a- ${ }^{--}$) were treated for 4 hours without or with $100 \mu \mathrm{M}$ nicotinic acid and $20 \mu \mathrm{g} / \mu \mathrm{I}$ IFN- $\gamma$ as indicated, and expression of MCP-1 mRNA was determined (mean values \pm SEM $[n=6]$ ). (B and C) MCP-1 expression in plaque macrophages (B) and expression of arginase-1 and arginase-2 in the CD68-postitive area (C) in untreated and nicotinic acid-treated atherosclerotic mice (mean \pm SEM; $n=5$ mice). (D) MCP-1-induced recruitment of peritoneal macrophages. Shown are mean values \pm SEM $(n=6)$. (E) Homing of WT and GPR109A-deficient (Gpr109a ${ }^{--}$) macrophages into atherosclerotic lesions. Shown is the number of macrophages homing into lesions of the aortic root 2 days after intravenous injection in the absence or presence of nicotinic acid. (F) CD68-positive macrophages in lesions of aortic

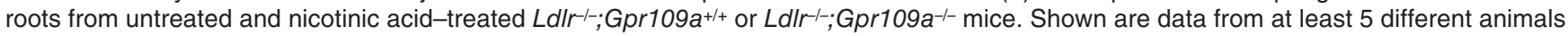
(mean values \pm SEM). (G) VCAM-1, ICAM-1, and P-selectin mRNA levels in aortae of Ldlr ${ }^{-1}$ mice that had been transplanted with Gpr109a $a^{+/+}$or Gpr109a-l- bone marrow. Animals were kept on a high-fat diet for 16 weeks and were treated without or with nicotinic acid (mean values \pm SEM $[n \geq 6]) .{ }^{*} P \leq 0.05 ;{ }^{* *} P \leq 0.01 ;{ }^{* *} P \leq 0.001$. 
efflux of cholesterol to HDL particles and that this effect depended on the presence of GPR109A. Despite the differences between our data on primary macrophages and those reported in macrophage cell lines, increasing evidence indicates that nicotinic acid enhances cholesterol transport out of macrophages.

In isolated macrophages, we observed that nicotinic acid inhibits the upregulation of MCP- 1 expression in response to IFN- $\gamma$, an effect which was absent in macrophages from GPR109A-deficient mice. Similarly, we also observed a decreased expression of MCP-1 in plaque macrophages after nicotinic acid treatment. Inhibition of the expression of inflammatory mediators by nicotinic acid was recently also shown in adipocytes in which nicotinic acid suppressed expression of various chemokines including MCP-1 while increasing the expression of adiponectin $(61,62)$. Since chemokines and nicotinic acid regulate cellular functions through receptors coupled to $\mathrm{G}_{\mathrm{i}}$-type $\mathrm{G}$-proteins $(63,64)$ and thereby initiate identical cellular signaling processes, it is conceivable that the activation of GPR109A by nicotinic acid given systemically can alter the effects of chemokines acting on the same cell. Consistent with that, we found in a model for MCP-1-induced chemotaxis in vivo that nicotinic acid inhibited the effect of MCP-1. This inhibitory effect was not seen in GPR109A-deficient mice. Thus, activation of GPR109A appears to interfere with chemokine effects. In adoptive transfer experiments with WT and GPR109A-deficient macrophages, we saw that nicotinic acid inhibited the homing of WT but not of receptor-deficient cells to atherosclerotic lesions of $\mathrm{ddl}^{-/}$- mice. Since MCP-1 and other chemokines are critical mediators of immune cell recruitment into the atherosclerotic vessel wall, a disturbance of chemokine signaling by nicotinic acid may contribute to the antiatherosclerotic effect of nicotinic acid. In this respect, it is interesting that activation of the cannabinoid receptor $\mathrm{CB}_{2}$, which is also coupled to $\mathrm{G}_{i}$-type G-proteins and which is expressed on immune cells including macrophages, reduces progression of atherosclerosis and inhibits macrophage chemotaxis by interfering with intracellular signaling processes induced through chemokine receptors (65-67).

Consistent with recent in vitro and in vivo data (32-34), we saw a reduced expression of adhesion molecules in atherosclerotic vessels of nicotinic acid-treated $\mathrm{Ldll}^{-/}$mice. The observed reduction in VCAM-1 and P-selectin mRNA levels were, however, not seen in Ldlr ${ }^{\prime-}$ mice transplanted with Gpr109a $a^{-/-}$bone marrow. In the case of VCAM-1 expression, we cannot rule out that part of the reduced expression in response to nicotinic acid is due to direct effects of nicotinic acid on plaque macrophages that also express VCAM-1. These data strongly indicate that the reduced expression was not due to direct effects of nicotinic acid on endothelial cells but involved activation of GPR109A on immune cells.

We also cannot exclude that other bone marrow-derived cells such as neutrophils, which have been shown to play a role in atherosclerosis progression (68), are involved in the antiatherosclerotic effects of nicotinic acid. Neutrophils express GPR109A, and nicotinic acid exerts a proapoptotic effect in neutrophils under in vitro conditions (40).

Our findings strongly indicate that nicotinic acid has direct effects on bone marrow-derived cells that are mediated by GPR109A and that these effects in addition to its antidyslipidemic effects are important for the antiatherosclerotic properties of this drug. Given the widespread expression of the nicotinic acid receptor GPR109A on immune cells, the antiinflammatory potential of nicotinic acid and other GPR109A agonists needs to be further explored. While new strategies to reduce inflammation and to increase reverse cho- lesterol transport by regulating the function of immune cells have been proposed as a new approach to treating atherosclerosis (69-71), our data show that one of the established antiatherosclerotic drugs in fact exerts its beneficial effect at least in part through mechanisms involving direct effects on leukocytes. These data strongly support a role for antiatherosclerotic mechanisms beyond lipid-altering effects and reveal what we believe is a new mechanism of action for one of the oldest drugs used to prevent and treat atherosclerosis.

\section{Methods}

Reagents and antibodies. A high-fat diet containing 21\% butter fat and $1.5 \%$ cholesterol was from ssniff. Nicotinic acid, oil red O, Brewer's thioglycollate medium, and recombinant mouse GM-CSF were from Sigma-Aldrich. Recombinant rat IFN- $\gamma$ was purchased at PeproTech, and recombinant mouse JE (MCP-1) was from Invitrogen. Macrophages were detected using rabbit anti-mouse macrophage antibodies (Accurate Chemical \& Scientific Corp.), rat anti-mouse MOMA-2 or anti-CD68 antibodies (Serotec), and goat antirabbit IgG or goat anti-rat IgG (Cy3) secondary antibodies (Alexa Fluor 488) from Invitrogen. Rabbit anti-mouse MCP-1 and rabbit anti-mouse arginase 2 antibodies were from abcam. Anti-arginase 1 antibody (BD Biosciences) was visualized with goat TRITC-labeled anti-mouse IgG (Invitrogen).

Genetic mouse models. Ldlr ${ }^{-}$mice were obtained from the Jackson Laboratory, and Gpr109a $a^{-/-}$mice have been described previously (20). The generation of a Gpr109a expression reporter mouse line (GPr109amRFP) was recently described (48). All experiments were performed with male mice, and the animals were kept on a C57BL/6 background. All procedures of animal care and use in this study were approved by the local authorities (Regierungspräsidium Darmstadt and Karlsruhe).

Determination of plasma lipid levels. Total cholesterol and triglyceride levels were determined in the plasma of nonstarved mice kept on a high-fat diet for the indicated time periods with assay kits from Sigma-Aldrich, and free fatty acid concentration was measured using an enzyme-based colorimetric assay kit from Randox according to the manufacturers' instructions. The distribution of cholesterol among different lipoprotein particles was analyzed by size-exclusion fast protein liquid chromatography (FPLC) followed by the determination of the cholesterol content in collected fractions. Serum samples were pooled and loaded $(200 \mu \mathrm{l})$ onto a Superose 6HR 10/30 column (Amersham), and lipoproteins were separated at a flow rate of $0.2 \mathrm{ml} / \mathrm{min}$ of PBS at $\mathrm{pH}$ 7.4. Fractions of $0.5 \mathrm{ml}$ were collected, and the cholesterol concentration was determined.

Bone marrow transplantation. Bone marrow was obtained aseptically from

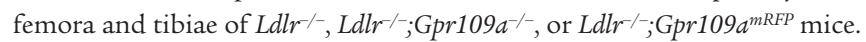
Cells $\left(5 \times 10^{6} /\right.$ mouse) were resuspended in sterile PBS and transplanted by intravenous infusion into lethally irradiated (10 Gy) $\mathrm{Ldll}^{/ /}$recipients 1 day after irradiation at the age of 8 weeks.

Induction and quantification of atherosclerosis. To induce atherosclerosis in $L d l r^{-/}$mice, animals were fed with a high-fat diet ad libitum for the indicated periods. Anesthetized animals were perfused with PBS via the left ventricle, followed by $4 \%$ paraformaldehyde, $5 \%$ sucrose, and $20 \mathrm{mM}$ EDTA in PBS, pH 7.4. After dissection and removal of adherent fat tissue, the aorta was immersed in the above buffer overnight. After removal of the adventitia, the aorta was opened longitudinally, pinned flat onto a dissecting wax, and stained with oil red O. Afterwards, aortae were mounted with glycerol gelatine onto a slide and photographed. The total aortic area and stained aortic lesion area were manually outlined in a blinded fashion and analyzed using Adobe Photoshop CS3, and the lesion size as a percentage of the total aortic area was determined. To evaluate atherosclerosis in the outflow tract and valve area of the heart, the top half of the heart was removed and immersed in the above buffer overnight followed by incubation in $30 \%$ sucrose. The hearts were embedded in OCT and stored at 
$-80^{\circ} \mathrm{C}$ until sectioning. Serial $10-\mu \mathrm{m}$ sections were cut through the part of the aortic root, where all 3 valve leaflets were present (72). For each mouse, sections separated by $50 \mu \mathrm{m}$ were examined systematically. Each section was stained with oil red $\mathrm{O}$ and mounted in glycerol gelatine. Sections were photographed and analyzed blinded using Adobe Photoshop CS3.

Fluorescence imaging of Gpr109 $a^{\text {mRFP }}$ and immunostained macrophages. Cryosections were fixed by incubation in $-20^{\circ} \mathrm{C}$ acetone for 2 minutes and rehydration in PBS. Endogenous peroxidase was quenched with $0.3 \%$ hydrogen peroxide. Nonspecific staining was blocked by incubation with $5 \%$ normal goat serum for 1 hour at room temperature. Sections were incubated overnight at $4^{\circ} \mathrm{C}$ with the following primary antibodies, either alone or in combination as indicated: polyclonal rabbit anti-mouse macrophage antiserum (1:100), rat anti-mouse MOMA-2 antibody (1:100), rat anti-mouse CD68 antibody (1:200), mouse anti-mouse arginase 1 antibody (1:100), rabbit anti-mouse arginase 2 antibody, and rabbit anti-mouse MCP- 1 antibody (1:100). Primary antibodies were visualized with fluorescently labeled Alexa Fluor 488-labeled goat anti-rabbit IgG, Cy3-labeled goat anti-rat IgG. or TRITC-labeled goat anti-mouse IgG secondary antibodies (1:200). Stained sections were mounted in Aqua-Poly/Mount medium and analyzed by confocal microscopy (Leica TCS SP2).

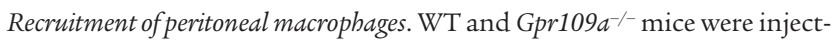
ed intraperitoneally with $1 \mathrm{ml}$ of autoclaved 4\% Brewer's thioglycollate medium. After 4 days, mice were injected intraperitoneally with $0.9 \% \mathrm{NaCl}$ or nicotinic acid (30 mg/kg) 1 hour prior to a second injection with $0.9 \%$ $\mathrm{NaCl}$ and murine MCP-1 (20 $\mu \mathrm{g} / \mathrm{kg})$ or nicotinic acid and murine MCP-1, as indicated. After 3 hours, peritoneal cells were collected by lavage with $15 \mathrm{ml}$ of PBS containing 5 mM EDTA and were counted.

Macrophage homing assay. Analysis of macrophages recruited into atherosclerotic lesions was performed with modifications as described $(73,74)$. Peritoneal macrophages were obtained as described above. 14 days prior to the isolation, donor mice were treated without or with $0.3 \%$ nicotin-

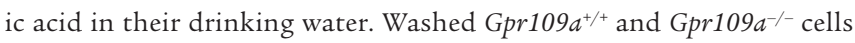
$\left(10^{6}\right.$ cells $\left./ 100 \mu \mathrm{l}\right)$ were labeled with quantum dot nanocrystals with different fluorescence emission maxima using Qtracker 525 and Qtracker 655 labeling kits (Invitrogen) according to manufacturer's instructions for 45 minutes at $37^{\circ} \mathrm{C}$. After washing, identical amounts $\left(10^{6} \mathrm{cells}\right)$ of labeled Gpr109a $a^{+/+}$and Gpr109a $a^{-/-}$cells were mixed and injected i.v. in $200 \mu \mathrm{l}$ PBS into recipient $L d l r^{-/}$mice that had been on a high-fat diet for 10 weeks. One day before macrophage injection, treatment of recipient mice without or with $0.3 \%$ nicotinic acid was started. After 48 hours, animals were sacrificed and perfused with PBS containing $4 \%$ paraformaldehyde, $5 \%$ sucrose, and $20 \mathrm{mM}$ EDTA in PBS, pH 7.4. Liver, spleen, and hearts were removed and immersed in the above buffer overnight followed by incubation in $30 \%$ sucrose. The organs were embedded in OCT and stored at $-80^{\circ} \mathrm{C}$ until sectioning. Liver and spleen sections served as internal controls. Cryosections $(8 \mu \mathrm{m})$ spanning the proximal $1 \mathrm{~mm}$ of the aortic valve region were collected, mounted in Aqua-Poly/Mount medium, and examined systematically. Fluorescent macrophages infiltrating the atherosclerotic lesions were counted.

Cholesterol efflux assay. Peritoneal macrophages were obtained as described above. 14 days prior to the isolation, donor mice were treated without or with $0.3 \%$ nicotinic acid in their drinking water. After washing, $5 \times 10^{5}$ cells/well were plated on $\mu$-slide 8 well (ibidi) in DMEM containing $10 \%$ FBS, $2 \mathrm{mM}$ glutamine, and $1 \mathrm{U} / \mathrm{ml}$ penicillin/streptomycin and were grown overnight. Thereafter, cells were loaded with NBD-cholesterol $(0.35 \mu \mathrm{M}$; Invitrogen) in the above medium containing $2.5 \% \mathrm{FBS}$ for 1 hour at $37^{\circ} \mathrm{C}$. Thereafter, cells were washed twice with Puck's buffer $\left(1 \mathrm{mM} \mathrm{Na}_{2} \mathrm{HPO}_{4}\right.$, $0.9 \mathrm{mM} \mathrm{H}_{2} \mathrm{PO}_{4}, 5 \mathrm{mM} \mathrm{KCl}, 1.8 \mathrm{mM} \mathrm{CaCl}_{2}, 0.6 \mathrm{mM} \mathrm{MgSO}_{4}, 6 \mathrm{mM}$ glucose, $138 \mathrm{mM} \mathrm{NaCl}$, and $10 \mathrm{mM} \mathrm{HEPES}$ ) and placed in serum-free medium. For the NBD-cholesterol efflux, HDL3 $(25 \mu \mathrm{g} / \mathrm{ml})$ prepared according to
Malaval et al. (75) was added, and the fluorescence in the total area of cells was recorded for 1 hour as described (76).

Expression analysis. Peritoneal macrophages were obtained by peritoneal lavage with $15 \mathrm{ml}$ of PBS containing $5 \mathrm{mM}$ EDTA 4 days after intraperitoneal injection of $1 \mathrm{ml}$ autoclaved $4 \%$ Brewer's thioglycollate medium. Cells were washed, plated on dishes in DMEM containing 10\% FBS, 2 mM glutamine, and $1 \mathrm{U} / \mathrm{ml}$ penicillin/streptomycin, and were incubated with GM-CSF $(20 \mathrm{ng} / \mathrm{ml})$ overnight. Cells were then washed to remove nonadherent cells and were then treated with vehicle or nicotinic acid $(100 \mu \mathrm{M}) 1$ hour prior to incubation with IFN- $\gamma$ in the absence or presence of nicotinic acid. Three hours later, cells were lysed, and total RNA was harvested using the RNeasy Micro Kit (QIAGEN). RNA from aortic arches or whole-mount aortae was isolated with RNeasy FFPE Kit (QIAGEN). Quantitative PCR was conducted in reactions containing cDNA from 600 ng total RNA (peritoneal macrophages and whole mount aortae) or 250 ng total RNA (aortic arches) with SYBR green indicator. PCR was performed in Chromo4 Real-Time Thermal Cycler using Opticon Monitor 3 software (Bio-Rad) or LightCycler 480 (Roche) for fluorescence detection and data evaluation. Data were analyzed with REST-384 software (77). Results are expressed as expression ratios of crossing threshold $(\mathrm{Ct})$ values for target genes normalized to the $\mathrm{Ct}$ of $\beta$-actin considering individual PCR efficiencies. The oligonucleotide primer sequences were as follows: MCP-1 forward: $5^{\prime}$-GCCAACTCTCACTGAAGCC-3', reverse: 5'-GCTGGTGAATGAGTAGCAGC-3' (78); ABCA1 forward: 5'-GGAGCTGGGAAGTCAACAAC-3', reverse: 5'-ACATGCTCTCTTCCCGTCAG-3'; ABCG1 forward: 5'-GCTGTGCGTTTTTGGCTGTT-3', reverse: 5'-TGCAGCTCCAATCAGTAGTCCTAA-3' (79); VCAM-1 forward: 5'-CCCCAAGGATCCAGAGATTCA-3', reverse: $5^{\prime}$ ACTTGACCGTGACCGGCTT-3'; ICAM-1 forward: 5'-ATCTCAGGCCGCAAGGG-3', reverse: 5'-CGAAAGTCCGGAGGCTCC-3'; P-selectin forward: 5'-CCGATGCCCTGCCCTCAC-3' , reverse: $5^{\prime}$-GGTCACTGCTGTCCATTGTCC- $3^{\prime}$; and $\beta$-actin forward: $5^{\prime}$-TGACGTTGACATCCGTAAAGAC-3', reverse: 5'-TGCTAGGAGCCAGAGCAGTAA-3' (80).

Statistics. All results are expressed as the mean $\pm \mathrm{SD}$, except where noted. Mean values between 2 groups were analyzed with 2-tailed $t$ test; data sets containing multiple groups were analyzed by ANOVA. $P<0.05$ was considered significant.

\section{Acknowledgments}

We thank Manuela Ritzal, Karin Meyer, the Nikon Imaging Center at the University of Heidelberg, and the lipidomic facilities (MetaToul platform) of the Bio-Medical Research Federative Institute of Toulouse (IFR150) for expert technical assistance and Rose LeFaucheur and Svea Hümmer for excellent secretarial help. S. Offermanns was supported by the German Research Foundation.

Received for publication November 3, 2009, and accepted in revised form December 15, 2010.

Address correspondence to: Stefan Offermanns, Department of Pharmacology, Max-Planck-Institute for Heart and Lung Research, Ludwigstr. 43, 61231 Bad Nauheim, Germany. Phone: 49.0.6032.705.1201; Fax: 49.0.6032.705.1204; E-mail: stefan. offermanns@mpi-bn.mpg.de.

Andreas Gille's present address is: CSL Ltd., Clinical and Translational Science Department, 45 Poplar Road, Parkville, Victoria 3052, Australia.

Jukka Kero's present address is: Department of Physiology, Institute of Biomedicine, Kiinamyllynkatu 10, 20520 Turku, Finland. 
1. Carlson LA. Nicotinic acid: the broad-spectrum lipid drug. A 50th anniversary review. J Intern Med. 2005;258(2):94-114.

2. Meyers CD, Kamanna VS, Kashyap ML. Niacin therapy in atherosclerosis. Curr Opin Lipidol. 2004; 15(6):659-665

3. Altschul R. Die Beeinflussung des Blutcholesterinspiegels und der experimentellen Ahterosklerose durch Nikotinsäure. Ztschr f Kreislaufforsch. 1956; 45:453-460.

4. Brattsand R, Lundholm L. The effect of nicotinic acid and pentaerythritolteranicotinate upon experimental atherosclerosis in the rabbit. Atherosclerosis. 1971;14(1):91-105.

5. Lundholm L, Jacobsson L, Brattsand R, Magnusson O. Influence of nicotinic acid, niceritrol and beta-pyridylcarbinol on experimental hyperlipidemia and atherosclerosis in mini-pigs. Atherosclerosis. 1978; 29(2):217-239.

6. Parwaresch MR, Haacke H, Mader C. Efficacy of hypolipidemic treatment in inhibition of experimental atherosclerosis: the effect of nicotinic acid and related compounds. Atherosclerosis. 1978; 31(4):395-401

7. Weitzel G, Wahl P, Buddecke E. Anti-atherosclerotic action of vitamin A compounds, nicotinic acid, beta-pyridyl compounds and arachidonic acid. Hoppe Seylers Z Physiol Chem. 1962;327:109-127.

8. Öst C-R. Regression of atherosclerosis during nicotinuic acid therapy: a study in man by means of repeated arteriographies. In: Altschul R, ed. Niacin In Vascular Disorders And Hyperlipemia. Springfield, Illinois, USA: Charles C. Thomas Publisher, LTD; 1964:245-262.

9. Blankenhorn DH, Johnson RL, Nessim SA, Azen SP, Sanmarco ME, Selzer RH. The Cholesterol Lowering Atherosclerosis Study (CLAS): design, methods, and baseline results. Control Clin Trials. 1987; 8(4):356-387.

10. Canner PL, et al. Fifteen year mortality in Coronary Drug Project patients: long-term benefit with niacin. J Am Coll Cardiol. 1986;8(6):1245-1255

11. Coronary Drug Project Research Group. Clofibrate and niacin in coronary heart disease. JAMA. 1975; 231(4):360-381.

12. Brown BG, et al. Simvastatin and niacin, antioxidant vitamins, or the combination for the prevention of coronary disease. N Engl J Med. 2001; 345(22):1583-1592.

13. Taylor AJ, Sullenberger LE, Lee HJ, Lee JK, Grace KA. Arterial Biology for the Investigation of the Treatment Effects of Reducing Cholesterol (ARBITER) 2: a double-blind, placebo-controlled study of extended-release niacin on atherosclerosis progression in secondary prevention patients treated with statins Circulation. 2004;110(23):3512-3517.

14. Lee JM, et al. Effects of high-dose modified-release nicotinic acid on atherosclerosis and vascular function: a randomized, placebo-controlled, magnetic resonance imaging study. J Am Coll Cardiol. 2009; 54(19):1787-1794.

15. Villines TC, et al. The ARBITER 6-HALTS Trial (Arterial Biology for the Investigation of the Treatment Effects of Reducing Cholesterol 6-HDL and LDL Treatment Strategies in Atherosclerosis): final results and the impact of medication adherence, dose, and treatment duration. J Am Coll Cardiol. 2010; 55(24):2721-2726.

16. Gille A, Bodor ET, Ahmed K, Offermanns S. Nicotinic acid: pharmacological effects and mechanisms of action. Annu Rev Pharmacol Toxicol. 2008; 48:79-106.

17. Digby JE, Lee JM, Choudhury RP. Nicotinic acid and the prevention of coronary artery disease. Curr Opin Lipidol. 2009;20(4):321-326.

18. Kamanna VS, Kashyap ML. Mechanism of action of niacin. Am J Cardiol. 2008;101(8A):20B-26B.

19. Soga T, et al. Molecular identification of nico- tinic acid receptor. Biochem Biophys Res Commun. 2003;303(1):364-369.

20. Tunaru S, et al. PUMA-G and HM74 are receptors for nicotinic acid and mediate its anti-lipolytic effect. Nat Med. 2003;9(3):352-355

21. Wise A, et al. Molecular identification of high and low affinity receptors for nicotinic acid. J Biol Chem. 2003;278(11):9869-9874.

22. Carlson LA. Studies on the effect of nicotinic acid on catecholamine stimulated lipolysis in adipose tissue in vitro. Acta Med Scand. 1963;173:719-722.

23. Kontush A, Chapman MJ. Functionally defective high-density lipoprotein: a new therapeutic target at the crossroads of dyslipidemia, inflammation, and atherosclerosis. Pharmacol Rev. 2006;58(3):342-374.

24. Joy T, Hegele RA. Is raising HDL a futile strategy for atheroprotection? Nat Rev Drug Discov. 2008; $7(2): 143-155$

25. Hernandez M, Wright SD, Cai TQ. Critical role of cholesterol ester transfer protein in nicotinic acidmediated HDL elevation in mice. Biochem Biophys Res Commun. 2007;355(4):1075-1080.

26. van der Hoorn JW, et al. Niacin increases HDL by reducing hepatic expression and plasma levels of cholesteryl ester transfer protein in APOE*3Leiden.CETP mice. Arterioscler Thromb Vasc Biol. 2008;28(11):2016-2022.

27. Lai E, et al. Abstract 190: A niacin receptor partial agonist, MK-0354, robustly reduces plasma free fatty acids and produces little flushing but fails to alter LDL-C, HDL-C, and triglycerides in humans. Circulation. 2007;116:II_16.

28. Semple G, et al. 3-(1H-tetrazol-5-yl)-1,4,5,6-tetrahydro-cyclopentapyrazole (MK-0354): a partial agonist of the nicotinic acid receptor, G-protein coupled receptor 109 a, with antilipolytic but no vasodilatory activity in mice. J Med Chem. 2008; 51(16):5101-5108.

29. Jin FY, Kamanna VS, Kashyap ML. Niacin decreases removal of high-density lipoprotein apolipoprotein A-I but not cholesterol ester by Hep G2 cells. Implication for reverse cholesterol transport. Arterioscler Thromb Vasc Biol. 1997;17(10):2020-2028.

30. Lamon-Fava $S$, et al. Extended-release niacin alters the metabolism of plasma apolipoprotein (Apo) A-I and ApoB-containing lipoproteins. Arterioscler Thromb Vasc Biol. 2008;28(9):1672-1678.

31. Ganji SH, Tavintharan S, Zhu D, Xing Y, Kamanna VS, Kashyap ML. Niacin noncompetitively inhibits DGAT2 but not DGAT1 activity in HepG2 cells. J Lipid Res. 2004;45(10):1835-1845

32. Ganji SH, Qin S, Zhang L, Kamanna VS, Kashyap ML. Niacin inhibits vascular oxidative stress, redox-sensitive genes, and monocyte adhesion to human aortic endothelial cells. Atherosclerosis. 2009; 202(1):68-75

33. Tavintharan S, Lim SC, Sum CF. Effects of niacin on cell adhesion and early atherogenesis: biochemi$\mathrm{cal}$ and functional findings in endothelial cells. Basic Clin Pharmacol Toxicol. 2009;104(3):206-210.

34. Wu BJ, Yan L, Charlton F, Witting P, Barter PJ, Rye KA. Evidence that niacin inhibits acute vascular inflammation and improves endothelial dysfunction independent of changes in plasma lipids. Arterioscler Thromb Vasc Biol. 2010;30(5):968-975.

35. Maciejewski-Lenoir D, et al. Langerhans cells release prostaglandin D2 in response to nicotinic acid. J Invest Dermatol. 2006;126(12):2637-2646.

36. Schaub A, Futterer A, Pfeffer K. PUMA-G, an IFN-gamma-inducible gene in macrophages is a novel member of the seven transmembrane spanning receptor superfamily. Eur J Immunol. 2001; 31(12):3714-3725.

37. Yousefi S, Cooper PR, Mueck B, Potter SL, Jarai G. cDNA representational difference analysis of human neutrophils stimulated by GM-CSF. Biochem Biophys Res Commun. 2000;277(2):401-409.

38. Tang H, Lu JY, Zheng X, Yang Y, Reagan JD. The psoriasis drug monomethylfumarate is a potent nicotinic acid receptor agonist. Biochem Biophys Res Commun. 2008;375(4):562-565.

39. Benyó Z, Gille A, Bennett CL, Clausen BE, Offermanns S. Nicotinic acid-induced flushing is mediated by activation of epidermal langerhans cells. Mol Pharmacol. 2006;70(6):1844-1849.

40. Kostylina G, Simon D, Fey MF, Yousefi S, Simon HU. Neutrophil apoptosis mediated by nicotinic acid receptors (GPR109A). Cell Death Differ. 2008; 15(1):134-142.

41. Meyers CD, Liu P, Kamanna VS, Kashyap ML. Nicotinic acid induces secretion of prostaglandin D2 in human macrophages: an in vitro model of the niacin flush. Atherosclerosis. 2007;192(2):253-258.

42. Richman JG, et al. Nicotinic acid receptor agonists differentially activate downstream effectors. $J$ Biol Chem. 2007;282(25):18028-18036.

43. Walters RW, et al. beta-Arrestin 1 mediates nicotinic acid-induced flushing, but not its antilipolytic effect, in mice. J Clin Invest. 2009;119(5):1312-1321.

44. Knowles HJ, Poole RT, Workman P, Harris AL. Niacin induces PPARgamma expression and transcriptional activation in macrophages via HM74 and HM74a-mediated induction of prostaglandin synthesis pathways. Biochem Pharmacol. 2006;71(5):646-656

45. Rubic T, Trottmann M, Lorenz RL. Stimulation of CD36 and the key effector of reverse cholesterol transport ATP-binding cassette A1 in monocytoid cells by niacin. Biochem Pharmacol. 2004;67(3):411-419.

46. Declercq V, Yeganeh B, Moshtaghi-Kashanian GR, Khademi H, Bahadori B, Moghadasian MH. Paradoxical effects of fenofibrate and nicotinic acid in apo E-deficient mice. J Cardiovasc Pharmacol. 2005;46(1):18-24.

47. Krause BR, Princen HM. Lack of predictability of classical animal models for hypolipidemic activity: a good time for mice? Atherosclerosis. 1998;140(1):15-24

48. Hanson J, et al. Nicotinic acid- and monomethyl fumarate-induced flushing involves GPR109A expressed by keratinocytes and COX-2-dependent prostanoid formation in mice. J Clin Invest. 2010; 120(8):2910-2919.

49. Mantovani A, Garlanda C, Locati M. Macrophage diversity and polarization in atherosclerosis: a question of balance. Arterioscler Thromb Vasc Biol. 2009; 29(10):1419-1423.

50. Glassberg H, Rader DJ. Management of lipids in the prevention of cardiovascular events. Annu Rev Med. 2008;59:79-94.

51. Expert Panel on Detection E, Treatment of High Blood Cholesterol in Adults. Executive Summary of the Third Report of The National Cholesterol Education Program (NCEP) Expert Panel on Detection, Evaluation, And Treatment of High Blood Cholesterol in Adults (Adult Treatment Panel III). JAMA. 2001;285(19):2486-2497.

52. Farmer JA. Nicotinic acid: a new look at an old drug. Curr Atheroscler Rep. 2009;11(2):87-92.

53. Kamanna VS, Ganji SH, Kashyap ML. Niacin: an old drug rejuvenated. Curr Atheroscler Rep. 2009; 11(1):45-51.

54. Chapman MJ. Therapeutic elevation of HDL-cholesterol to prevent atherosclerosis and coronary heart disease. Pharmacol Ther. 2006;111(3):893-908.

55. Duffy D, Rader DJ. Update on strategies to increase HDL quantity and function. Nat Rev Cardiol. 2009; $6(7): 455-463$

56. Kontush A, Guerin M, Chapman MJ. Spotlight on HDL-raising therapies: insights from the torcetrapib trials. Nat Clin Pract Cardiovasc Med. 2008; 5(6):329-336.

57. Olsson AG. Is high HDL cholesterol always good? Ann Med. 2009;41(1):11-18.

58. Nicholls SJ. HDL: still a target for new therapies? Curr Opin Investig Drugs. 2008;9(9):950-956. 
59. Gleissner CA, Shaked I, Little KM, Ley K. CXC chemokine ligand 4 induces a unique transcriptome in monocyte-derived macrophages. J Immunol. 2010; 184(9):4810-4818.

60. Yvan-Charvet L, Wang N, Tall AR. Role of HDL, $\mathrm{ABCA} 1$, and ABCG1 transporters in cholesterol efflux and immune responses. Arterioscler Thromb Vasc Biol. 2010;30(2):139-143.

61. Digby JE, McNeill E, Dyar OJ, Lam V, Greaves DR, Choudhury RP. Anti-inflammatory effects of nicotinic acid in adipocytes demonstrated by suppression of fractalkine, RANTES, and MCP-1 and upregulation of adiponectin. Atherosclerosis. 2010;209(1):89-95.

62. Plaisance EP, Lukasova M, Offermanns S, Zhang Y, Cao G, Judd RL. Niacin stimulates adiponectin secretion through the GPR109A receptor. Am J Physiol Endocrinol Metab. 2009;296(3):E549-558.

63. Offermanns S. The nicotinic acid receptor GPR109A (HM74A or PUMA-G) as a new therapeutic target. Trends Pharmacol Sci. 2006;27(7):384-390.

64. Horuk R. Chemokine receptors. In: Offermanns S, Rosenthal W, eds. Enyclopedia of Molecular Pharmacology. New York, New York, USA: Springer Verlag; 2008:351-355.

65. Raborn ES, Marciano-Cabral F, Buckley NE, Martin BR, Cabral GA. The cannabinoid delta9-tetrahydrocannabinol mediates inhibition of macrophage chemotaxis to RANTES/CCL5: link- age to the CB2 receptor. J Neuroimmune Pharmacol. 2008;3(2):117-129.

66. Montecucco F, Burger F, Mach F, Steffens S. $\mathrm{CB}_{2}$ cannabinoid receptor agonist JWH-015 modulates human monocyte migration through defined intracellular signaling pathways. Am J Physiol Heart Circ Physiol. 2008;294(3):H1145-H1155.

67 . Steffens $\mathrm{S}$, et al. Low dose oral cannabinoid therapy reduces progression of atherosclerosis in mice. Nature. 2005;434(7034):782-786.

68. Weber C, Zernecke A, Libby P. The multifaceted contributions of leukocyte subsets to atherosclerosis: lessons from mouse models. Nat Rev Immunol. 2008;8(10):802-815.

69. Hansson GK, Libby P. The immune response in atherosclerosis: a double-edged sword. Nat Rev Immunol. 2006;6(7):508-519.

70. Liang CP, Han S, Senokuchi T, Tall AR. The macrophage at the crossroads of insulin resistance and atherosclerosis. Circ Res. 2007;100(11):1546-1555.

71. Duffy D, Rader DJ. Emerging therapies targeting high-density lipoprotein metabolism and reverse cholesterol transport. Circulation. 2006;113(8):1140-1150.

72. Daugherty A, Rateri DL. Hyperlipidemia-induced atherosclerosis. In: Xu Q, ed. A Handbook of Mouse Models of Cardiovascular Disease. London, United Kingdom: John Wiley and Sons, Ltd; 2006:43-66.

73. Gareus R, et al. Endothelial cell-specific NF-kap-
paB inhibition protects mice from atherosclerosis. Cell Metab. 2008;8(5):372-383.

74. Cuff CA, et al. The adhesion receptor CD44 promotes atherosclerosis by mediating inflammatory cell recruitment and vascular cell activation. J Clin Invest. 2001;108(7):1031-1040.

75. Malaval C, et al. RhoA/ROCK I signalling downstream of the P2Y13 ADP-receptor controls HDL endocytosis in human hepatocytes. Cell Signal. 2009;21(1):120-127.

76. Atshaves BP, et al. Sterol carrier protein-2 expression modulates protein and lipid composition of lipid droplets. J Biol Chem. 2001;276(27):25324-25335.

77. Pfaffl MW, Horgan GW, Dempfle L. Relative expression software tool (REST) for group-wise comparison and statistical analysis of relative expression results in real-time PCR. Nucleic Acids Res. 2002;30(9):e36.

78. Dol-Gleizes F, et al. Rimonabant, a selective cannabinoid CB1 receptor antagonist, inhibits atherosclerosis in LDL receptor-deficient mice. Arterioscler Thromb Vasc Biol. 2009;29(1):12-18.

79. Ouvrier A, et al. LXR and ABCA1 control cholesterol homeostasis in the proximal mouse epididymis in a cell specific manner. J Lipid Res. 2009;50(9):1766-1775.

80. Rieken S, et al. G12/G13 family G-proteins regulate marginal zone B cell maturation, migration and polarization. J Immunol. 2006;177(5):2985-2993. 